OnLine Journal of Biological Sciences 12 (1): 18-20, 2012

ISSN 1608-4217

(C) 2012 A.B. Koli et al., This open access article is distributed under a Creative Commons Attribution

(CC-BY) 3.0 license

\title{
Sugar Utilization Potential of Micropolyspora Isolated from Extreme Environment
}

\author{
${ }^{1}$ Koli, A.B., ${ }^{2}$ Prakash Thorat and ${ }^{1}$ S.W. Kulkarni \\ ${ }^{1}$ Research Department of Microbiology, \\ Shriman Bhausaheb Zadbuke Mahavidyalaya, Barshi, 413401, Dist. Solapur, M.S, India \\ ${ }^{2}$ Department of Microbiology and Research Center, \\ Shri Shivaji Mahavidyalaya, Barshi-413 411, Dist-Solapur, MS, India
}

\begin{abstract}
Problem statement: Waste water of various industries contain large amount of organic compounds which are continuously added in sea via river which causes water pollution. There is need to degrade the organic content to abate water pollution. Approach: To stabilize the organic content in sea water, there was need to search such an organism which was efficient to degrade organic content. We had screened the actinomycetes having potential to degrade organic compounds. Results: Total six isolates of Micropolyspora were obtained, from which all isolates were found to utilize galactose, $50 \%$ isolates were able to utilize arabinose, fructose and xylose. $83 \%$ of isolates showed mannitol utilization while $67 \%$ isolates uses lactose as carbon source and 33\% isolates utilizes rhamnose. Conclusion/Recommendation: From the study performed, we conclude that, obtained most of Micropolyspora isolate may be used for the stabilization of organic content and hence in abatement of pollution.
\end{abstract}

Key words: Marine environment, Micropolyspora, sugar utilization, waste water, abatement

\section{INTRODUCTION}

The hydrosphere marine environment represents the major component of Earth biosphere. Ocean represents a vast and exhaustive source of natural products in the globe, harboring the most diverse group of flora and fauna. Marine microorganisms have developed unique metabolic and physiological capabilities to thrive in extreme habitats and produce novel metabolites which are not often present in microbes of terrestrial origin (Mincer et al., 2002). Ocean is largely unexploited or underexploited source of new potentially bioactive substances having great diversity.

There is tremendous diversity and novelty among the marine actinomycetes present in marine environments. As marine environmental conditions are extremely different from terrestrial ones, it is surmised that marine actinomycetes have different characteristics from those of terrestrial counterparts. Because of extraordinary conditions like extremely high pressure, low light and anaerobic conditions in deep sea and high salinity, alkalinity and low nutrient content, generic and metabolic diversity is different in marine actinomycetes; which remains largely unknown (Lam, 2006).

However, distribution of actinomycetes in the sea is largely unknown or unexplored. This is partly caused by lack of efforts spent in exploring marine actinomycetes.
Pollution of marine water is major problem because of shipping and presence of large number of textile industries nearby to seashore. Along with this sea water is polluted by mixing polluted river water with it.

Waste of Sugar industry, paper industry, textile industry, starchy product based industrial wastes; distilleries contain higher concentration of organic compound. This waste water is released in river and through which it get mixed into sea water this results into water pollution of marine ecosystem.

Pollution of oceans by the effluents released from these industries is proving a great problem for the marine life. Therefore, there is need to degrade the pollutants or reduce the pollution by biological control.

Actinomycetes have ability to degrade the complex substances. Bensultana et al. (2010) used actinomycetes for the preparation of waste water sand filters. Their findings indicate that antagonistic actinomycetes have potential involvement in removal of waste water associated pathogen.

Nocardia are interesting environmental organisms since, they are able to metabolise sterols and steroids found in animal wastes. They are also able to decompose rubber and other complex hydrocarbons found in many industrial wastes. In recent years, Nocardia have been implicated in the production of

Corresponding Author: Koli A.B., Research Department of Microbiology, Shriman Bhausaheb Zadbuke Mahavidyalaya, Barshi, 413401, Dist. Solapur, M.S, India 
heavy scum on the surface of activated sludge aeration tanks, treating domesting sewage and various industrial wastes (McKinney, 2004).

Various carbohydrates utilization like mellibiose, raffinose, stachyose, lactose, sucrose. was tested to study the extent of degradation of oligosaccharides by Lyons et al. (1969).

Proser and Palleroni (1978) studied nutritional characterization of actinomycetes. They found that there are number of actinomycetes which utilizes variety of sugars for their growth. D-arabinose, Lfucose, sucrose and quinate are substrates used by the four strains of Nocardia maditerranei and by relatively few of Streptomyces strain.

In the present study, actinomycetes were isolated from marine water, mud and sand samples to test their potential of sugar utilization. So that, these actinomycetes may have major role in degradation of waste which is carbohydrate in nature.

\section{MATERIALS AND METHODS}

- Marine water sample, mud sample and sand sample from Goa and Janjira beach (M.S, India)

- Glycerol aspargine agar

- Shirling and Gottlieb medium with $1 \%$ sugar like arabinose, fructose, rhamnose, mannitol, galactose, xylose, lactose. separately

Isolation and identification: Different marine samples were streak inoculated on glycerol aspargine agar (Glycerol- $1 \mathrm{~g}$, L-aspargine- $0.1 \mathrm{~g}, \mathrm{~K}_{2} \mathrm{HPO}_{4}-0.1 \mathrm{~g}$, Trace salt solution- $0.1 \mathrm{~mL}$, agar powder- $2.5 \mathrm{~g}$, distilled water-100 mL, $\mathrm{pH}-7.4)$ and incubated at room temperature for 4-7 days.

Isolated organisms were identified as actinomycetes on the basis of morphological and cultural characteristics.

Morphological studies were carried out by coverslip culture technique and slide culture technique (Mycelium Pattern e.g., Aerial, Submerged and Surface mycelia and Structure of spore chain).

The organisms were identified on the basis of cultural characteristics grown on different growth media viz. Bennet's agar and Dextrose agar and spore chain morphology; they were further studied for their sugar utilization potential.

Sugar utilization pattern: The isolates were spot inoculated on Shirling and Gottlieb medium $\left[\left(\mathrm{NH}_{4}\right)_{2}\right.$ $\mathrm{SO}_{4}-2.64 \mathrm{~g}, \mathrm{KH}_{2} \mathrm{PO}_{4}-2.38 \mathrm{~g}, \mathrm{~K}_{2} \mathrm{HPO}_{4}-5.65 \mathrm{~g}$, $\mathrm{MgSO}_{4} .7 \mathrm{H}_{2} \mathrm{O}-1.0 \mathrm{~g}$, Trace salt solution-1.0 mL, agar- 20g, Distilled Water $1000 \mathrm{~mL}, \mathrm{pH}-7.2]$ having $1 \%$ of various sugars like arabinose, fructose, rhamnose, mannitol, galactose, xylose, lactose. separately (Shirling and Gottlieb, 1966).These plates were incubated at room temperature for 4-7 days.

Results were recorded on the basis of presence or absence of growth.

\section{RESULTS}

Isolation and identification: The organisms were isolated on glycerol aspargine agar and identified as Micropolyspora on the basis of morphological and cultural characteristics by using Bergey's Manual of Systematic Bacteriology vol. 4 (Bergey et al.,1989) and MICRO-IS Software.

Sugar utilization pattern: Result of sugar utilization pattern was recorded in Table 1.

All Micropolyspora species utilizes galactose, $83 \%$ of isolates found to utilize mannitol, $67 \%$ isolates were showed growth on lactose while $50 \%$ of Micropolyspora species were able to utilize arabinose, fructose and xylose. Remaining 33\% isolates utilizes rhamnose as carbon source.

\section{DISCUSSION}

Garcia-Dominguez et al. (1989) reported that the wild type isolate of Streptomyces clavuligerus and gut1 mutant have ability to utilize hexoses (glucose, mannose, galactose and fructose), pentose (xylose), deoxysugars (rhamnose), sugar alcohols (glycerol, inositol, mannitol and sorbitol), disaccharides (maltose, sucrose and lactose) and polysaccharide (starch) of which glycerol, maltose and starch were used efficiently as carbon sources by the wild type isolate.

Table 1: Pattern of sugar utilization of Micropolyspora

\begin{tabular}{|c|c|c|c|c|c|c|c|}
\hline Isolate No. & Arabinose & Fructose & Lactose & Rhamnose & Mannitol & Xylose & Galactose \\
\hline$\overline{\mathrm{BMA}_{2}}$ & - & + & $?$ & - & + & - & + \\
\hline $\mathrm{BMA}_{3}$ & + & ? & + & + & + & + & + \\
\hline $\mathrm{CMA}_{2}$ & + & + & + & $?$ & + & + & + \\
\hline $\mathrm{JWA}_{1}$ & + & + & + & + & + & + & + \\
\hline $\mathrm{JWA}_{2}$ & - & - & - & - & - & - & + \\
\hline $\mathrm{JSA}_{2}$ & $?$ & - & + & $?$ & + & $?$ & + \\
\hline
\end{tabular}

Where: + = Positive; BMA = Baga Mud Actinomycetes; - = Negative; CMA = Calangut Mud Actinomycetes; + = Slight utilization; JWA = Janjira Water Actinomycetes; ? = May be; JSA = Janjira Sand Actinomycetes 
It have been reported that the strains of Streptomyces coalicolor were grown on medium containing glucose, mannose, fructose, maltose, lactose, starch, mannitol. separately while other strains were not able to use Dfucose and inulin (Proser and Palleroni, 1978).

In comparison to these findings, we have also reported the potential of sugar utilization in Micropolyspora species isolated from marine environment. These sugars include galactose, mannitol, lactose, arabinose, fructose, xylose and rhamnose.

\section{CONCLUSION}

The Micropolyspora species were having potential to stabilize organic content in sea water hence, denote their role in abatement of pollution, in terms of organic content.

\section{ACKNOWLEDGEMENT}

Researchers are thankful to the Principal of Shriman Bhausaheb Zadbuke Mahavidyalya Barshi for providing laboratory and library facilities to carry out this study.

\section{REFERENCES}

Bensultana, A., Y. Ouhdouch, L. Hassani, N.E. Mezrioui and L. Rafouk, 2010. Isolation and characterization of wastewater sand filter actinomycetes. World J. Microbiol. Biotechnol., 26: 481-487. DOI: 10.1007/s11274-009-0194-0
Bergey, D.H., S.T. Williams, J.G. Holt and N.R. Krieg, 1989. Bergey's Manual of Systematic Bacteriology. 9th Edn., Wiliams and Wilkins, London, ISBN: 0683090615, pp: 2648.

Garcia-Dominguez, M., J.F. Martin and P. Liras, 1989. Characterization of sugar uptake in wild-type Streptomyces clavuligerus, which is impaired in glucose uptake and in a glucose-utilizing mutant. J. Bacteriol., 12: 6808-6814.

Lam, K.S., 2006. Discovery of novel metabolites from marine actinomycetes. Current Opinion Microbiol., 9: 245-251. DOI: 10.1016/j.mib.2006.03.004

Lyons, A.J. Jr., T.G. Pridham and C.W. Hesseltine, 1969. Survey of some actinomycetales for $\alpha$ galactosidase activity. Applied Microbiol., 18: 579-583.

McKinney, 2004. Environmental Pollution Control Microbiology. 1st Edn., CRC Press, ISBN-10: 0824757971, pp: 448.

Mincer, T.J., P.R. Jensen, C.A. Kauffman and W. Fenical, 2002. Widespread and persistent populations of a major new marine actinomycete taxon in ocean sediments. Applied Environ. Microbiol., 68: 5005-5011. DOI: 10.1128/AEM.68.10.5005-5011.2002

Proser, B.L.T. and N.J. Palleroni, 1978. Nutritional characterization of some selected actinomycetes. Int. J. Syst. Bacteriol., 28: 516-522. DOI: 10.1099/00207713-28-4-516

Shirling, E.B. and D. Gottlieb, 1966. Methods for characterization of Streptomyces species. Int. J. Syst. Bacteriol., 16: 313-340. DOI: 10.1099/00207713-16-3-313 